\title{
建筑工程中节能施工技术的应用
}

马利

秦皇岛荣盛房地产开发有限公司，河北秦皇岛 066000

DOI:10.33142/ec.v2i 2.168

[摘要] 随着经济与科技的快速发展, 建筑行业也取得了硕大的成果。当前建筑工程规模不断扩大, 节能技术在建筑工程 施工中的应用越来越广泛, 极大的推动了绿色建筑的快速发展。众所周知, 建筑工程在施工过程中需要耗费大量的资 源与材料, 而且对于环境来说存在着一定的破坏, 将节能施工技术应用于建筑工程施工中, 能够最大化的利用资源, 实现可持续发展的道路。

[关键词]建筑工程; 绿色节能; 施工技术; 应用

\section{Application of Energy-saving Construction Technology in Building Engineering} Ma Li

\section{Qinhuangdao Rongsheng Real Estate Development Co., Ltd., Qinhuangdao, Hebei,China 066000}

\begin{abstract}
With the rapid development of economy and science and technology, the construction industry has made great achievements. At present, the scale of building project is expanding constantly, and the application of energy-saving technology in the construction of building engineering is more and more extensive, which greatly promotes the rapid development of green building. As we all know, the construction engineering needs a lot of resources and materials in the construction process, and there is a certain damage to the environment. The application of energy-saving construction technology to the construction project maximizes the utilization of resources and realizes the road of sustainable development.
\end{abstract}

Keywords:Building engineering; Green-energy saving; Construction technology; Application

引言

在建筑工程建设中充分应用绿色节能技术, 不仅能够有效突出建筑工程管理的科学性, 还能有效提高建筑整体的 绿色节能效果, 使建筑物的能源消耗量以及对周边环境的影响得到有效降低。绿色节能技术在建筑工程中应用时, 需 要贯穿整个工程建设的全过程, 所以, 设计人员以及施工人员必须要谨慎把握, 制定完善的绿色节能施工技术应用制度, 确保绿色节能技术的应用效果，使其作用得到更加充分的发挥，进而提高建筑工程的节能性以及环保性。

1 建筑工程施工应用节能技术的意义

目前, 随着我国人口数量的不断增多及工业发展速度的不断加快, 能源消耗量也在持续增加, 进一步加重了我国 能源紧张问题, 很大程度的限制了我国经济发展。所以, 在建筑工程施工中应用节能技术是具有很大意义的, 节能施 工技术的应用能够使建筑工程的节能减排效果大大提高, 能够实现资源利用率的提高, 从而防止能源浪费问题的发生。 在资源鿒乏的今天, 绿色建筑因其能够有效解决自 然资源与人类资源消耗之间的矛盾, 从而成为世界建筑 发展的主流。 绿色节能建筑大概有 3 个重要的地方: (1) 要考虑到建筑物自身的生态可持续发展性, 建造出即能利于生态环境, 又 能利于国民经济的建筑。（2）在以人们身心健康为前提条件上, 营造健康环保舒适的生活与工作的环境。（3）要最 大限度地节约能源和保护自然环境，同时，需要保证建筑物质量不会出现问题，质量过关。

建筑工程施工中应用节能技术是具有很大意义的, 主要体现在以下几个方面:

1.1 保护环境

建筑工程施工过程中, 需要使用到大量的不可再生资源, 且会给周边环境带来非常大的破坏, 在实际施工中, 施 工企业一般都是注重于效益, 却没有加强对施工环保性以及节能性的重视。而通过对节能技术的应用, 则能够使建筑 工程的节能性及环保性得到有效提高, 能够对环境起到较好的保护作用。

\section{2 带动相关的技术发展}

节能技术并不是一种简单技术, 该技术充分融入了大量的科学技术以及高端先进技术, 通过对节能技术的应用, 能够有效带动其他技术的发展。 


\section{3 实现我国建筑事业的新发展}

在建筑工程施工中应用节能施工技术, 不但可以有效提高建筑工程施工质量, 还能有效加快建筑工程施工进度, 施工期得到有效缩短，进而促进我国建筑事业的健康稳定发展。

\section{4 有利于推动新能源的开发}

合理应用节能技术, 还能使人们减轻对不可再生资源的依赖性, 能够使可再生能源得到更加充分的利用, 比如太 阳能以及风能等，有效推动我国新型能源的开发与利用。

\section{5 有助于提高建筑的整体水平}

将节能技术应用在建筑工程施工中, 还可以有效促进施工技术的完善与创新, 能够使建筑的整体水平得到很大程 度的提高。

\section{2 建筑节能的难点 \\ 2.1 噪音扰民}

超过 120 分贝的声音对人类生活来讲就已经是噪音了, 而工程施工各类大型机械的使用, 发出的声音远远超过噪 音的标准, 施工人员在噪音较大的施工现场必须佩戴耳塞, 能够减轻一些噪音的困扰, 但是周围环境的噪音污染确实 不好控制。无论是土石方、打桩或者最后竣工拆卸脚手架的工作，每一个环节都有多种机械设备工作，而且每一个环 节产生的噪音污染也是不同的。其他污染可以通过加强管理、提高认识等等方法进行预防和规范, 但是施工正常工作, 而产生的噪音又该如何处理。所以说, 噪音扰民是建筑工程施工中要主要绿色环保一个十分重要的基本点 ${ }^{[3]}$ 。

\section{2 废水废气处理}

建筑施工过程中需要大量的水, 无论是施工人员的生活用水还是工程用水都会造成极大的污染。桩基阶段会产生 大量的泥浆, 泥浆流动慢而密度又高, 导入下水管道极容易造成堵塞, 然后出现下水道溢满现象, 反而加剧了水污染。 如果不导入下水管道或者施工地点偏僻没有下水管道, 直接排放更是污染了土地, 破坏植被生长, 也经常造成施工场 所环境卫生一片狼藉。废气的产生多出自施工初期阶段和装修工程。施工中使用的粉末类建材, 形成粉尘扬沙, 建筑 地点偏僻没有配套的公路建设, 工程运输在土路中进行造成粉土飞扬。装修工程中很多装修材料都甲醛超标, 沥青、 涂料、油漆等材料都具有高浓度挥发性的化合物分子, 在空气中进行传播, 影响动物的生存环境, 对植被生长产生刺激, 对人体的免疫系统、呼吸系统都造成极大地危害。

\section{3 建筑施工技术中节能技术的应用 \\ 3.1 门窗材料及安装节能}

在建筑工程建设中, 门窗是必不可少的一个构件, 随着人们生活质量的不断提高, 对门窗的要求也在不断提升。 所以, 为了满足人们的实际需求, 并保证建筑整体的节能性以及环保性, 在对门窗材料进行选择的时候, 需要选择质 量以及节能性较高的门窗材料, 比如塑料单框双玻门窗。再对门窗材料进行安装的时候, 必须要做好对门窗结构的测量, 避免出现误差, 进而防止门窗在使用过程中出现严重的变形。同时, 在门窗安装过程中, 安装施工人员还应当严格按 照施工要求来进行安装操作, 细心做好每一个安装环节, 不能马虎了事, 从而确保门窗安装质量, 提高门窗的节能水平。

\section{2 推广装配式混凝土建筑}

装配式混凝土建筑是指以工厂化生产的钢筋混凝土预制构件为主, 通过现场装配的方式设计建造的混凝土结构类 房屋建筑。一般分为全装配建筑和部分装配建筑两大类: 全装配建筑一般为低层或抗震设防要求较低的多层建筑; 部 分装配建筑的主要构件一般采用预制构件, 在现场通过现浇混凝土连接, 形成装配整体式结构的建筑物。该建筑物的 特点是, 施工速度快, 利于冬期施工, 生产效率高, 产品质量好, 减少了物料损耗。

\section{3 墙体节能施工技术的应用}

建筑工程中, 墙体发挥着非常重要的保温作用, 所以, 墙体的施工对于实现节能建筑建设来说也是至关重要的, 如果墙体施工质量不达标的话, 那么建筑整体的保温性能就会大大下降, 进而增加建筑的能源消耗。所以, 在对建筑 墙体进行施工的时候, 必须要加强质量控制, 确保墙体的施工质量能够符合相关标准, 使其保温性能得到更加充分的 发挥, 减少建筑能源消耗, 进一步提高建筑整体的节能效果。再对建筑墙体节能施工技术进行选择的时候, 需要充分 考虑当地的天气条件以及环境条件, 确保墙体节能技术选择的合理性, 从而提高墙体的节能施工效果, 为实现建筑整 体节能奠定良好的基础。

\section{4 节能采光}

建筑工程节能施工中, 往往都会采用自然光来进行采光, 这样能有效降低建筑的能源消耗。通常来讲, 采光技术 主要有两种, 一种是直接采光技术, 另一种是间接采光技术。直接采光技术是建筑工程施工中应用最为广泛的一种采 光技术, 但是其却具有着很高的局限性, 再对节能采光技术进行选择的时候, 必须要充分考虑建筑工程现场的实际情况, 确保节能采光技术选择的合理性，从而提高建筑整体的节能性，降低建筑能源消耗量。

\section{5 屋顶节能}


由于屋顶的位置是受到阳光照射时间最长, 且阳光辐射度最强的区域, 是建筑施工中最为重要的建筑结构。因此, 对建筑的屋顶进行隔热以及保温处理, 能够降低屋顶建筑的具体能源消耗。当前, 建筑的屋顶施工都是混凝土的形式, 在后期的使用过程中会出现冬冷夏热的现象, 给人们的生活带来不良的影响。因此, 在屋顶建筑当中使用节能的技术, 能够有效避免这种现象的发生。其主要是在建筑屋顶加设隔热层, 最好是选择轻质材料的隔热层, 能够将屋顶的热能 得到充分利用，还能使屋顶具有良好的隔热以及保温的功效，有效防止冬天冷、夏天热的现象发生。

\section{4 结语}

在以往的建筑施工中受到技术和条件的制约, 造成了对环境的污染和能源的浪费。但是现在科技进步、设备先进, 应该在此基础上重视节能减排和绿色环保的意义, 切实将可持续发展的理念带到建筑工作中来, 真正落实节能减排、 绿色环保。

\section{[参考文献]}

[1] 蒲秦伟。试论节能施工技术在建筑工程中的应用 [J]. 现代经济信息, 2018, 8 (20): 343 .

[2] 温钦成. 绿色节能施工技术在房屋建筑工程中的应用 [J].智能城市, 2018, 4 (14): 96-97.

[3] 屈华. 节能施工技术在工民建建筑工程的应用 [J].信息化建设, 2016, $7(03): 124$.

[4] 董军科. 探讨节能施工技术在建筑工程中的运用 [J].中华民居 (下旬刊), 2013, 6 (02) : 114-115.

[5] 赵文瑜.刍议节能施工技术在工民建建筑工程中的应用 [J].广东科技, 2012, 21 (15): 228-240. 